\title{
Role of GSTM1 and GSTT1 Polymorphism: Susceptibility to Oral Submucous Fibrosis in the North Indian Population
}

\author{
Deepa Agrawal $^{\mathrm{a}}$ Shalini Gupta ${ }^{\mathrm{b}}$ Deepti Agarwal ${ }^{\mathrm{d}} \quad$ Om Prakash Gupta ${ }^{\mathrm{b}}$ \\ Mohit Agarwalc \\ ${ }^{a}$ Cardiovascular Toxicology Division, Indian Institute of Toxicology Research, and Departments of \\ ${ }^{b}$ Oral Pathology and ${ }^{C}$ Oral and Maxillofacial Surgery, and ${ }^{\mathrm{d}}$ Faculty of Dental Sciences, Chhatrapati Shahuji \\ Maharaj Medical University (formerly KGMU), Lucknow, India
}

\section{Key Words}

GSTM1 · GSTT1 • Oral submucous fibrosis • Polymorphism • Glutathione s-transferases

\begin{abstract}
Molecular epidemiological studies have provided evidence that individual susceptibility to cancer is mediated by both genetic and environmental factors. Several allelic variants of polymorphic glutathione s-transferases (GSTs) show impaired enzyme activity and are suspected to increase the host's susceptibility to various cancers. To determine the association of GST variants with the risk of oral submucous fibrosis (OSF), the distribution of polymorphisms in GSTM1 and GSTT1 was studied in 90 OSF patients and 130 healthy controls. Genotypic analysis was performed by multiplex $P C R$. The relationship between the null genotypes and the risk of OSF was assessed by means of odds ratios (OR) with 95\% confidence intervals $(\mathrm{Cl})$ calculated by logistic regression. The frequency of both the GSTM1 and GSTT1 null genotypes was higher in the OSF cases than in the controls. The prevalence of the GSTM1 null genotype in the OSF cases was $46.6 \%$ as compared to $29.2 \%$ in the controls (OR $2.12,95 \% \mathrm{Cl}$ 1.2-3.9) and GSTT1 null was $24.4 \%$ in the OSF cases versus
\end{abstract}

$10.7 \%$ in the controls (OR 2.68, 95\% Cl 1.22-5.96). There was evidence of an increased risk with the absence of both genotypes (7.5-fold; OR 7.5, 95\% Cl 2.3-24). Our findings suggest that the GSTM1 and GSTT1 null genotypes, separately or in combination, increase the risk of developing OSF in the North Indian population.

Copyright $\odot 2011$ S. Karger AG, Basel

\section{Introduction}

Oral submucous fibrosis (OSF), first described in the early 1950s, is a debilitating, potentially cancerous oral, oropharyngeal, and at times esophageal mucosal condition caused primarily by chewing areca nuts, a habit commonly seen among South Asian people [1]. OSF may be considered a multihit process of aberrant genetic events following the action of various carcinogens which are products of tobacco, smoking, alcohol, and betel [2-4]. Various epidemiological studies [5-7] have shown that it is the leading precancerous condition and has the highest recorded incidences in developing countries $[7,8,9]$. A precancerous condition is defined as a generalized state associated with a significantly increased risk of cancer

\section{KARGER}

Fax +41613061234 E-Mail karger@karger.ch www.karger.com
(C) 2011 S. Karger AG, Base

0030-2414/10/0794-0181\$26.00/0

Accessible online at:

www.karger.com/ocl
Deepa Agrawal

Cardiovascular Toxicology Division

Indian Institute of Toxicology Research (formerly ITRC)

PO Box No. 80, M.G. Marg, Lucknow, UP 226001 (India)

Tel. +91 522262 7586, Fax+91 522262 8227, E-Mail dr_deepaagrawal@ rediffmail.com 


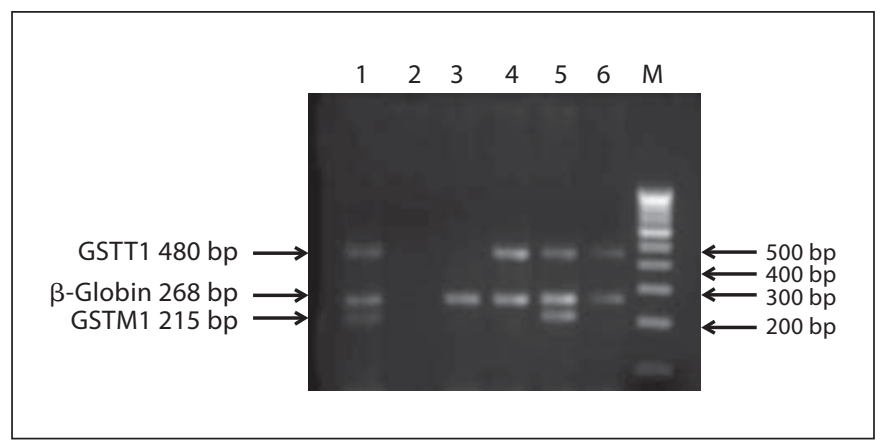

Fig. 1. Agarose gel demonstrating multiplex PCR genotyping of GSTM1 and GSTT1 gene deletion (null genotype). The absence of a 480-bp band indicates the GSTT1 null genotype. The absence of a 215-bp band indicates the GSTM1 null genotype. $\beta$-Globin was coamplified in all of the samples. Lanes 1 and 5 represent the GSTM1 and GSTT1 positive genotype. Lanes 4 and 6 represent the GSTM1 null genotype. Lane 2 represents the negative control, and lane 3 represents the GSTM1 and GSTT1 null genotypes. M marker $=100$-bp DNA ladder.

development. The disease mostly affects $\sim 0.5 \%$ (5 million people) of the population in the Indian subcontinent [10] and is currently a public health issue in many parts of the world, including the UK [11], South Africa [6], and many southeastern Asian countries [7, 8].

A major clinical symptom of OSF is trismus, a limited ability to open the mouth, which eventually impairs the ability to eat and speak and may make dental care difficult. Various case-control, cohort, and intervention studies have provided supporting evidence that areca nuts are the main etiological factor in OSF $[5,9,12,13]$. An oral precancerous condition (PCC) such as OSF is an early indicator of damage to the oral mucosa with a malignant transformation rate of 3-19\% [14].

The inherited differences in the effectiveness of the detoxification/activation of carcinogens play a crucial role in host susceptibility. Most of the carcinogenic moieties are metabolically processed by xenobiotic metabolizing enzymes in 2 broad steps: phase I which is mediated by cytochrome P450 (CYPs) and phase II which is catalyzed by glutathione s-transferases (GSTs) [15]. In humans, allelic forms of GSTs are known, often resulting in changed efficiencies of that particular enzyme. Consequently, this may result in genetically controlled reactive metabolites or a larger persistence (and thus availability) of a reactive substance in the body. The coordinated expression of phase I and phase II enzymes determines the outcome of carcinogen exposure [16, 17]. Genetic polymorphism affects the expression or activity of the meta- bolic enzymes responsible for the detoxification of tobacco and alcohol and are therefore thought to influence individual susceptibility to cancer [18-20]. GSTs play an important role in the metabolism of chemical carcinogens, especially with regard to those present in tobacco smoke and betel nuts [21, 22]. GSTs prevent the initiation of the carcinogenic process by inactivating or detoxifying electrophilic carcinogens. During the initiation and promotion stage, specialized forms of GSTs are expressed and initiated in precancerous and cancerous cells [23]. GSTM1 and GSTT1 are polymorphic and their deleted variants (null genotypes) result in a complete loss of functional activity $[24,25]$.

Various studies have shown a positive association between the GSTM1 and GSTT1 null genotypes and an increased risk of bladder, skin, lung, and oral cancer [2527]. Therefore, the present study aimed to detect the frequency of GST polymorphisms (GSTM1 and GSTT1) and to determine the susceptibility to OSF.

\section{Subjects and Methods}

\section{Study Subjects}

The present case-control study comprised 90 patients with OSF and 130 geographically and racially matched healthy controls. The study was initiated following approval from the institutional ethical review board. The patients had either reported for treatment of OSF or had been diagnosed with OSF during a routine oral examination. The criteria for diagnosis was based on the presence of fibrous bands in the labial and/or buccal mucosa, loss of the elasticity of the buccal/labial mucosa, and the inability to open the mouth, along with a positive history of areca nuts or tobacco in any form. The inclusion criterion for the controls was absence of a prior history of cancer or any other oral lesions.

Consent was obtained from all patients and controls and a comprehensive clinical history including various oral habits and their frequency (number of times per day), duration (years of consumption), and type (areca nuts, pan masala, or betel quid), along with tobacco and alcohol use was taken. After obtaining patients' informed consent, 2-ml blood samples were collected in sterile EDTA vials. DNA was isolated from frozen blood samples using the proteinase K phenol-chloroform method [28].

\section{GSTM1 and GSTT1 Genotyping}

Amplifications of the GSTM1 and GSTT1 genotypes were obtained simultaneously in a single approach using a multiplex PCR method. Briefly, each $25 \mu \mathrm{l}$ of reaction mixture contained $200 \mu \mathrm{M}$ dNTPs, $10 \times$ PCR buffer of $1.5 \mu \mathrm{M} \mathrm{MgCl}_{2}$, and 0.5 units of Taq polymerase. Genomic DNA (100-150 ng) was amplified together with 20 pmol of each pair of the following primers: GSTM1 primer (5'-GAA CTC CCT GAA AAG CTA AGC-3' and 5'-GTT GGG CTC AAA TAT ACG GTG G-3') and GSTT1 primers (5'-TTC CTT ACT GGT CCTCC ATC TC-3' and 5'-TCA CCG GAT CAT GGA AAC CA-3'). $\beta$-Globin primers (5'-CAA CTT CAT CCA 
Table 1. Frequency of the GSTM1 and GSTT1 genotypes in OSF patients and controls

\begin{tabular}{llllll}
\hline Polymorphism & $\begin{array}{l}\text { Cases } \\
(\mathrm{n}=90)\end{array}$ & $\begin{array}{l}\text { Controls } \\
(\mathrm{n}=130)\end{array}$ & OR & $95 \% \mathrm{CI}$ & $\begin{array}{l}\mathrm{p} \\
\text { value }\end{array}$ \\
\hline $\begin{array}{l}\text { GSTM1 } \\
\text { Present }\end{array}$ & $48(53.3 \%)$ & $92(70.7 \%)$ & 1 & - & \\
$\quad$ Null & $42(46.6 \%)$ & $38(29.2 \%)$ & 2.12 & $1.2-3.9$ & $0.012^{*}$ \\
GSTT1 & & & & - \\
$\quad$ Present & $68(75.5 \%)$ & $116(89.2 \%)$ & 1 & $1.2-5.96$ & $0.012^{*}$ \\
$\quad$ Null & $22(24.4 \%)$ & $14(10.7 \%)$ & 2.68 & & \\
\hline
\end{tabular}

Table 2. Testing for a trend in the risk of OSF associated with 1 or more putative high-risk GST genotypes

\begin{tabular}{|c|c|c|c|c|c|c|}
\hline \multicolumn{2}{|c|}{ GST status } & \multirow{2}{*}{$\begin{array}{l}\text { Cases } \\
(\mathrm{n}=90)\end{array}$} & \multirow{2}{*}{$\begin{array}{l}\text { Controls } \\
(\mathrm{n}=130)\end{array}$} & \multirow[t]{2}{*}{ OR } & \multirow[t]{2}{*}{$95 \% \mathrm{CI}$} & \multirow{2}{*}{$\begin{array}{l}\mathrm{p} \\
\text { value }\end{array}$} \\
\hline GSTM1 & GSTT1 & & & & & \\
\hline Present & Present & $41(45.5 \%)$ & $82(63 \%)$ & 1 & - & - \\
\hline Present & Null & $7(7.7 \%)$ & $10(7.6 \%)$ & 1.40 & $0.49-3.9$ & 0.71 \\
\hline Null & Present & $27(30 \%)$ & $34(26.1 \%)$ & 1.59 & $0.84-2.97$ & 0.20 \\
\hline Null & Null & $15(16.6 \%)$ & $4(3.07 \%)$ & 7.50 & $2.3-24$ & $0.0004^{*}$ \\
\hline
\end{tabular}

CGT TCA CC-3' and 5'-GAA GAG CCA AGG ACA GGT AC-3') were used as a positive control.

The reaction conditions were initial denaturation at $94^{\circ} \mathrm{C}$ for $5 \mathrm{~min}$ followed by 35 cycles at $94^{\circ} \mathrm{C}$ for $1 \mathrm{~min}, 58^{\circ} \mathrm{C}$ for $1 \mathrm{~min}$, $72^{\circ} \mathrm{C}$ for $1 \mathrm{~min}$, and a final polymerization step at $72^{\circ} \mathrm{C}$ for $10 \mathrm{~min}$. The amplified products were analyzed by electrophoresis on ethidium bromide-stained $2 \%$ agarose gels. The presence of a band at $268 \mathrm{bp}$ (corresponding to $\beta$-globin) indicated a successful amplification. The presence or absence of a band at 215 and 480 bp determined wild or deletion genotypes of GSTM1 and GSTT1, respectively.

\section{Statistical Analysis}

The relationship between the GSTM1 and GSTT1 genotypes and the risk of OSF was assessed by means of odds ratios (OR) with $95 \%$ confidence intervals (CI) calculated by logistic regression. GSTM1 and GSTT1 genotypes were classified as either null (homozygous deletion) or nondeleted. A $\chi^{2}$ test was used to determine the presence of an increase in the risk of OSF in patients with more than 1 putative high-risk allele or genotype. All computational analyses were performed using statistical software package SYSTAT 6.0 .

\section{Results}

Ninety patients with OSF (71 males and 19 females; mean age \pm SD: $43 \pm 15.3$ years) were included in the study. Control blood samples were obtained from 130 un- related healthy individuals (84 males and 46 females; mean age \pm SD: $40.8 \pm 10.3$ years). In the controls the frequency of the GSTM1 and GSTT1 null genotypes was $29.2 \%(38 / 130)$ and $10.7 \%(14 / 130)$, respectively (table 1). The frequency of the GSTM1 and GSTT1 null genotypes in the OSF patients was found to be significantly higher, i.e. $46.6 \%(42 / 90)$ and $24.4 \%(22 / 90)$ as compared to the controls (OR 2.12, 95\% CI 1.2-3.9 and OR 2.68, 95\% CI 1.22-5.96, respectively).

In order to assess the correlation between the 2 GST genotypes, the frequency of the presence of 2 putative 'high-risk' genotypes was calculated. Individuals carrying both low-risk genotypes, the non-deleted GSTM1 and GSTT1 genotypes, served as the reference group (table 2). The frequency of GSTM1 and GSTT1 genes in the patients and controls was 45.5\% (41/90) and 63\% (82/130), respectively. The frequency of the GSTM1 and GSTT1 null genotypes in the controls was $7.6 \%$ (10/130) and $26.1 \%(34 / 130)$. The frequency of these null genotypes was higher in the OSF cases, i.e. 7.7\% (7/90) and 30\% (27/90), respectively, whereas the frequency for both null genotypes in the OSF cases and the controls was $16.6 \%$ (15/90) and 3.07\% (4/130), respectively. There was a 7.5fold increase in the risk of OSF patients compared to the controls (OR 7.50, 95\% CI 2.3-24). 


\section{Discussion}

OSF, a chronic progressive disorder, and its clinical presentation depend on the stage of the disease at the time of detection. It is apparent that fibrosis and hyalinization of subepithelial tissues account for most of the clinical features encountered in this condition. Moreover, research on elucidating its etiology and pathogenesis appears to have been focused on changes in the extracellular matrix. There are numerous biological pathways involved in the aforementioned processes, and it is likely that the normal regulatory mechanisms are either downregulated or upregulated at different stages of the disease [29]. Its influence on the overlying epithelium is not known, but about $3-19 \%$ of OSF cases undergo a malignant transformation to squamous cell carcinoma [14]. Many investigators have studied the pathogenesis of OSF. It is characterized by epithelial atrophy with a disappearance of the rete pegs as well as by inflammatory cell infiltration and the accumulation of collagen fibers within the lamina propria [30-32]. Increased mitotic activity and epithelial hyperplasia have also been reported in OSF and oral leukoplakia [30-33]. Thus, OSF has been considered a precancerous lesion [30].

Data from recent epidemiological studies provide overwhelming evidence that areca nuts are the main etiological factor in OSF. A clear dose-dependent relationship was observed for both the frequency and the duration of chewing areca nuts in the development of the disease. Commercially freeze-dried products such as pan masala (betal nut, lime, cardamom, menthol, and added flavors), gutka (betal nut, tobacco, lime, saffron, and added colors), and mawa (areca nut and lime) have high concentrates of areca nuts per chew and appear to cause OSF more rapidly than self-prepared conventional betel that contains smaller amounts of areca nuts. Among the chemical constituents, the most important biologically active compounds are alkaloids from areca nuts. Four alkaloids conclusively identified from areca nuts in studies are arecoline, arecaidine, guvacine, and guvacoline, with arecoline being the main agent. These chemicals appear to interfere with the molecular process of the deposition and/or degradation of extracellular matrix molecules such as collagens [11].

Genetic polymorphism has been described in the enzymes involved in the metabolism of tobacco carcinogens and cancer risks. It is determined by the degree of expression and/or activity of the enzymes involved in the activation or deactivation of carcinogens. Most of the carcinogens are lipophilic and require conversion into water-sol- uble hydrophilic compounds for easy removal from the body through the excretory system. GSTs, the multifunctional enzymes, facilitate detoxification, thus protecting cells from oxidative stress [20] and individual susceptibility to cancer risk [34]. Very few studies that can correlate GST genotypes (GSTM1 and GSTT1) and OSF have been conducted $[34,35]$.

Ethnic differences in the prevalence of GSTM1 null genotypes have been reported to vary between 22 and $35 \%$ in Africans, between 38 and $67 \%$ in Caucasians, and between 33 and $63 \%$ in the East Asian population. The GSTT1 null genotype varies from 10 to $18 \%$ in Caucasians $[20,24]$ and is about $58 \%$ in the Chinese population. The polymorphism of GSTM1 and GSTT1 genes and their effect on oral diseases was studied recently in several countries. A study on oral leukoplakia conducted in India revealed that null genotypes of GSTM1 and GSTT1 are high-penetrance risk factors for developing oral leukoplakia [36].

In our study, we observed a higher frequency of the GSTM1 and GSTT1 null genotypes in the OSF patients as compared to the controls [42/90 (46.6\%) vs. $38 / 130$ (29.2\%); OR 2.12, 95\% CI 1.2-3.9] and [22/90 (24.4\%) vs. $14 / 130$ (10.7\%); OR 2.68, 95\% CI 1.22-5.96], and the results were statistically significant (OR 7.5, 95\% CI 2.3-24; $\mathrm{p}<0.05)$. A case-control study from India on OSF patients reported no significant difference in the allelic variants of GSTM1 between OSF patients and controls, while the GSTT1 null genotype showed significantly higher frequencies in this precancerous condition [37]. The association of the GSTM1 null genotype with a slight increase in the risk of developing oral cancer, leukoplakia, and OSF has also been reported elsewhere $[35,38,39]$. We observed the prevalence of the GSTM1 and GSTT1 null genotypes to be 29.2 and $10.7 \%$ among the 130 healthy controls. The prevalence of the GSTM1 null genotype in Asian Indians from Malaysia was reported to be $33-36 \%[40,41]$, whereas the prevalence of the GSTT1 null genotype in Indians from Malaysia and Singapore was $16 \%$; double deletion was seen in only $5 \%$ of these subjects [42]. The data confirms that there are large ethnic differences in the prevalence of these polymorphic GST enzymes which are known to catalyze the detoxification of tobacco-derived carcinogens [43].

There was a significantly higher prevalence of the GSTM1 and GSTT1 null genotypes in the OSF cases, i.e. 15/90 (16.6\%). The individuals with both the GSTM1 and GSTT1 null genotypes had a 7.5-fold higher risk of OSF as compared to the subjects with either the GSTM1 or the GSTT1 null genotype (OR 7.5, 95\% CI 2.3-24) (table 2). 
In conclusion, our results revealed that null genotypes of both GSTM1 and GSTT1, either individually or in combination, influence the risk of developing OSF. It has been reported that GSTM1 is involved in the detoxification of polycyclic aromatic hydrocarbons and other mutagens, and that cells from GSTM1 null individuals are more susceptible to the DNA damage caused by these agents [44]. The development of OSF is multifactorial; additional environmental and genetic parameters could also be a risk factor. The results are promising, but a study with a larger sample size is still needed for further explanation.

\section{Acknowledgements}

The authors wish to thank the director of the Indian Institute of Toxicology Research, Lucknow, for his support. We are thankful to Richa Chandra and Deepmala Yadav (project assistants), as well as to Neeraj Mathur (biostatistician) for helping with the experiment and the statistical analysis. We acknowledge the cooperation received from all of the subjects who participated in the study. The financial support from the CSIR Suprainstitutional Project (SIP-08) in carrying out this study is also gratefully acknowledged.

\section{References}

1 International Agency for Research on Cancer: Betel Quid and Areca Nut Chewing and Some Areca Nut Derived Nitrosamines. Lyon, IARC, 2004, pp 123-129.

2 Rothman K, Keller A: The effect of joint exposure to alcohol and tobacco on risk of cancer of the mouth and pharynx. J Chronic Dis 1972;25:711-716.

-3 Blot WJ, McLaughlin JK, Winn DM, Austin DF, Greenberg RS, Preston-Martin S, et al: Smoking and drinking in relation to oral and pharyngeal cancer. Cancer Res 1988;48: 3282-3287.

4 Day GL, Blot WJ, Austin DF: Racial differences in risk of oral and pharyngeal cancer: alcohol, tobacco and other determinants. J Natl Cancer Inst 1993;85:465-473.

5 Murti PR, Bhonsle RB, Gupta PC, Daftary DK, Pindborg JJ, Metha FS: Etiology of oral submucous fibrosis with special reference to the role of areca nut chewing. J Oral Pathol Med 1995;24:145-152.

6 Seedat HA, van Wyk CW: Betel-nut chewing and submucous fibrosis in Durban. S Afr Med J 1988;74:568-571.

7 Zain RB, Ikeda N, Razaki H, Axell T, Majid ZA, Gupta PC, et al: A national epidemiological survey of oral mucosal survey of oral mucosal lesions in Malaysia. Community Dent Oral Epidemol 1997;25:377-383.

-8 Maher R, Lee AJ, Warnakulasuriya KA, Lewis JA, Johnson NW: Role of areca nut in the causation of oral submucous fibrosis: a case-control study in Pakistan. J Oral Pathol Med 1994;23:65-69.

-9 Ranganathan K, Devi MU, Joshua E, Kirankumar K, Saraswathi TR: Oral submucous fibrosis: a case-control study in Chennai, South India. J Oral Pathol Med 2004;33:274277.

10 Chiu CJ, Chang ML, Chiang CP, Hahn LJ, Hsieh LL, Chen CJ: Interaction of collagenrelated genes and susceptibility to betel quidinduced oral submucous fibrosis. Cancer Epidemiol Biomarkers Prev 2002;11:646-653.
11 Jacob BJ, Straif K, Thomas G, Ramdas K, Mathew B, Zhang ZF, et al: Betel quid without tobacco as a risk factor for oral precancers. Oral Oncol 2004;40:697-704.

12 Shah N, Sharma PP: Role of chewing and smoking habits in the etiology of oral submucous fibrosis (OSF): a case control study. J Oral Pathol Med 1998;27:475-479.

13 Caniff JP, Harvey W, Harris M: Oral submucous fibrosis: its pathogenesis and management. Br Dent J 1986;160:429-434.

14 Auluck A, Rosin MP, Zhang L, Sumanth KN: Oral submucous fibrosis, a clinically benign but potentially malignant disease: report of 3 cases and review of the literature. J Can Dent Assoc 2008;74:735-740.

15 Gajecka M, Rydzanicz M, Jaskula-Sztul R, Kujawski M, Szyfter W, Szyfter K: CYP1A1, CYP2D6, CYP2E1, NAT2, GSTM1 and GSTT1 polymorphisms or their combinations are associated with the increased risk of the laryngeal squamous cell carcinoma. $\mathrm{Mu}$ tat Res 2005;574:12-23.

16 Bartsch H, Nair U, Risch A, Rojas M, Wikman H, Alexandrov K: Genetic polymorphism of CYP genes, alone or in combination, as a risk modifier of tobacco-related cancers. Cancer Epidemiol Biomarkers Prev 2000;9:3-28.

17 Boffetta P, Hashibe M: Alcohol and Cancer. Lancet Oncol 2006;7:149-156.

18 Geisler SA, Olshan AF: GSTM1, GSTT1 and risk of squamous cell carcinoma of head and neck: a mini-huge review. Am J Epidemiol 2001;154:95-105.

19 Brennan P, Boffetta P: Mechanistic considerations in the molecular epidemiology of head and neck cancer. IARC Sci Publ 2004;393314.

20 Parl FF: Glutathione S-transferase genotypes and cancer risk. Cancer Lett 2005;221:123129.
21 Hashibe M, Brenman P, Strange RC, et al: Meta- and pooled analysis of GSTM1, GSTT1, GSTP1 and CYP1A1 genotypes and risk of head and neck cancer. Cancer Epidemiol Biomarkers Prev 2003;12:1509-1517.

22 Peters ES, McClean MD, Liu M, Eisen EA, Mueller N, Kelsey KT: The ADHIC polymorphism modifies the risk of squamous cell carcinoma of the head and neck associated with alcohol and tobacco use. Cancer Epidemiol Biomarkers Prev 2005; 14:476-482.

23 Gambashidze K, Kipiani N, Topurize M: Biophysical and biochemical parameters of organism during experimental malignant tumour growth. Am Biomed Res Educ 2002; 2:196-203.

24 Seidegard J, Pero RW, Markowitz MM, Roush G, Miller DG, Beattie EJ: Isoenzyme(s) of glutathione transferase (class $\mu$ ) as a marker for the susceptibility to lung cancer: a follow-up study. Carcinogenesis 1990;11: 33-36.

25 Naveen AT, Adithan C, Padmaja N: Glutathione S-transferases M1 and T1 null genotype distribution in South Indians. Eur J Clin Pharmacol 2004;60:403-406.

26 Gronau S, Koenig-Greger D, Jerg M, Riechelmann H: Gene Polymorphism in detoxification enzymes as susceptibility factor for head and neck cancer? Otolaryngol Head Neck Surg 2003;128:674-680.

27 Srivastava DS, Mandhani A, Mittal B, Mittal RD: Genetic polymorphism of glutathione S-transferase genes (GSTM1, GSTT1 and GSTP1) and susceptibility to prostate cancer in Northern India. BJU Int 2005;95:170-173.

28 Sambrook J, Russel DW: Molecular Cloning: A Laboratory Manual, ed 3. New York, Cold Spring Harbour, 2001.

29 Tilakarante WM, Klinikowski MF, Saku T, Peters TJ, Warnakulasuriya S: Oral submucous fibrosis: review on aetiology and pathogenesis. Oral Oncol 2006;42:561-568. 
-30 Pindborg JJ, Chawla TN, Srivastava AN, Gupta D: Epithelial changes in oral submucous fibrosis. Acta Odontol Scand 1965;23: 277-286.

-31 Shiau YY, Kwan HW: Submucous fibrosis in Taiwan. Oral Surg Oral Med Oral Pathol 1979;47:453-457.

-32 Mani NJ, Singh B: Studies on oral submucous fibrosis. III. epithelial changes. Oral Surg Oral Med Oral Pathol 1976;41:203-214.

-33 Wahi PN, Luthra UK, Kapur VL: Submucous fibrosis of the oral cavity: histomporphological studies. Br J Cancer 1966;20:676-687.

-34 Anantharaman D, Chaubal PM, Kannan S, Bhisey RA, Mahimkar MB: Susceptibility to oral cancer by genetic polymorphisms at CYP1A1, GSTM1 and GSTT1 loci among Indians: tobacco exposure as a risk modulator. Carcinogenesis 2007;28:1455-1462.

-35 Bathi RJ, Rao R, Mutalik S: GST null genotype and antioxidants: risk indicators for oral pre-cancer and cancer. Indian J Dent Res 2009;20:298-203.
36 Nair UJ, Nair J, Mathew B, Bartsch H: Glutathione S-transferase M1 and T1 null genotypes as risk factors for oral leukoplakia in ethnic Indian betel quid/tobacco chewers. Carcinogenesis 1999;20:743-748.

37 Pal M, Chaudhuri SR, Jadav A, Banerjee S, Paul RR, Dutta PK, et al: Quantitative dimensions of histopathological attributes and status of GSTM1-GSTT1 in oral submucous fibrosis. Tissue Cell 2008;40:425-435.

38 Oshan AF Weissler MC, Watson MA, Bell DA: GSTM1, GSTT1, GSTP1, CYP1A1, and NAT1 polymorphisms, tobacco use, and the risk of head and neck cancer. Cancer Epidemol Biomarkers Prev 2000;9:185-191.

39 Trizna Z, Clayman GL, Spitz MR, Briggs KL, Goepfert H: Glutathione s-transferase genotypes as risk factors for head and neck cancer. Am J Surg 1995;170:499-501.

40 Lin HJ, Han CY, Bernstein DA, Hsiao W, Lin BK, Hardy S: Ethnic distribution of the glutathione transferase Mu 1-1 (GSTM1) null genotype in 1,473 individuals and application to bladder cancer susceptibility. Carcinogenesis 1994;15:1077-1081.
41 Zhao B, Lee EJ, Wong JY, Yeoh PN, Gong $\mathrm{NH}$ : Frequency of mutant CYP1A1, NAT2 and GSTM1 alleles in normal Indians and Malays. Pharmacogenetics 1995;5:275-280.

42 Lee EJ, Wong JY, Yeoh PN, Gong NH: Glutathione S-transferase-theta (GSTT1) genetic polymorphism among Chinese, Malays and Indians in Singapore. Pharmacogenetics 1995;5:332-334.

$\checkmark 43$ Nelson HH, Wiencke JK, Christiani DC, Cheng TJ, Zuo ZF, et al: Ethnic differences in the prevalence of the homozygous deleted genotype of glutathione S-transferase theta. Carcinogenesis 1995;16:1243-1245.

44 Strange RC, Fryer AA: The glutathione Stransferases: influence of polymorphism on cancer susceptibility; in Vineis P, Malats N, Lang M, d'Errico A, Caporaso N, Cuzick J, Boffetta P (eds): Metabolic Polymorphisms and Susceptibility to Cancer. Lyon, IARC, 1999, pp 231-249. 